\title{
GSTM1 and GSTT1 polymorphisms in endometriosis in women from Goiás, Brazil
}

\author{
A.B. Frare ${ }^{1,2,3}$, A.M. Barbosa ${ }^{3}$, I.R. Costa ${ }^{2,3,4}$, S.R. Souza ${ }^{1,2}$, R.C.P.C. Silva ${ }^{2,3}$, \\ B.M. Bordin ${ }^{2,3,4}$, C.L. Ribeiro Júnior ${ }^{2}$ and K.K.V.O. Moura ${ }^{3,4}$ \\ ${ }^{1}$ Especialista em Reprodução Humana, \\ Pontifícia Universidade Católica de Goiás, Goiânia, GO, Brasil \\ ${ }^{2}$ Mestre em Genética, Pontifícia Universidade Católica de Goiás, \\ Goiânia, GO, Brasil \\ ${ }^{3}$ Núcleo de Pesquisa Replicon, Pontifícia Universidade Católica de Goiás, \\ Goiânia, GO, Brasil \\ ${ }^{4}$ Departamento de Biomedicina, Pontifícia Universidade Católica de Goiás, \\ Goiânia, GO, Brasil
}

Corresponding author: A.B. Frare

E-mail: arianeufg@yahoo.com.br

Genet. Mol. Res. 12 (3): 2764-2770 (2013)

Received January 10, 2012

Accepted March 14, 2013

Published August 2, 2013

DOI http://dx.doi.org/10.4238/2013.August.2.1

\begin{abstract}
Endometriosis is a gynecologic pathology with a high prevalence and unknown etiology. Therefore, an increasing number of studies has been undertaken to search for associations between endometriosis and alterations or polymorphisms in candidate genes, including glutathione S-transferase mu 1 (GSTM1) and glutathione $S$-transferase theta 1 (GSTT1). We analyzed the frequency of present/absent polymorphisms of GSTM1 and GSTT1 in 50 women diagnosed with endometriosis and in a control group of 46 women without complaints related to this pathology. The association of these polymorphisms with p53 gene codon 72 was also evaluated within each group, and a higher frequency of absence of GSTM1 (61\%) and GSTT1 $(45 \%)$ genes in the group of women studied, women with endometriosis and control group was found. The contributions of GSTM1 and
\end{abstract}


GSTT1 polymorphisms to the proliferation of endometriosis were not statistically significant, but the analysis of pathology and the association of GSTM1 and GSTT1 gene polymorphisms with p53 codon 72 revealed statistical significance.

Key words: Endometriosis; Infertility, GSTM1; GSTT1

\section{INTRODUCTION}

Endometriosis is the presence of functional endometrial stromal glands outside the uterine cavity. Three different forms of endometriosis are possible - rectovaginal, cystic ovarian, and peritoneal - each with its own pathogenesis, symptoms, natural history, and treatment (Dunselman et al., 2001). The etiology of endometriosis is unknown, although a multifactorial origin from a combination of immunological, genetic, and environmental factors is considered the most plausible (Porpora et al., 2009).

The prevalence of endometriosis in asymptomatic women is $2-50 \%$ depending on the diagnostic criteria used and the population studied. The prevalence in women with dysmenorrhea is $40-60 \%$. In women with subfertility, the prevalence is $20-30 \%$ (Farquhar, 2007). Endometriosis is the most common cause of pelvic pain and occurs in 13-33\% of women with infertility (Kyama et al., 2003). Its prevalence and severity are reportedly increasing in developing countries (Porpora et al., 2009). Between 20 and $40 \%$ of women with infertility have endometriosis. Among young women with chronic pelvic pain unresponsive to hormonal therapy or treatment with nonsteroidal anti-inflammatory drugs, the prevalence of endometriosis is approximately $70 \%$ (Halis et al., 2010).

The production of reactive oxygen species by peritoneal fluid seems to be increased in women with endometriosis, and altered expression of enzymes involved in bodily defense against oxidative stress has also been observed in the endometria of women with this condition. Excessive production of reactive oxygen species may also be a result of exposure to environmental compounds that disrupt the balance between pro-oxidants and antioxidants (Nakata et al, 2004).

Recently, several genetic studies have revealed an association between the development of endometriosis and certain genetic polymorphisms. However, the genes that play a role in the susceptibility to and progression of endometriosis remain unknown (Attar et al., 2010).

The diagnosis of endometriosis is usually made based on clinical history, as the results of physical examination are often normal (Jackson and Telner, 2006). The most definitive test to diagnose endometriosis is laparoscopic visualization of typical lesions and biopsy, but these procedures are not always necessary. The level of pain does not always correlate with the severity diagnosed laparoscopically. Of all lesions and biopsies, only $45 \%$ confirm endometriosis. Negative results of diagnosis by laparoscopy are accurate for excluding endometriosis (Jackson and Telner, 2006). A large body of evidence demonstrates an association between endometriosis and infertility. Endometriosis is found in up to 50\% of infertile women (American Society for Reproductive Medicine, 2012).

The role of glutathione $S$-transferase (GST) polymorphisms as a risk factor for endometriosis has been extensively researched. GSTs are key enzymes of phase II that catalyze the conjugation of glutathione to numerous potentially genotoxic compounds. Although the results are not entirely consistent, several studies have suggested a correlation between endometriosis 
and the GST mu 1 (GSTM1) or GST theta 1 (GSTT1) genotypes (Ertunc et al., 2005). Given the detoxifying properties of the GST family of enzymes, a lack of function or reduction in detoxifying enzymes owing to a deletion polymorphism may predispose women to endometriosis (Guo, 2005).

\section{MATERIAL AND METHODS}

\section{Subjects and samples}

Fifty samples were collected from women (mean age, 33.2 years) with laparoscopyconfirmed endometriosis, and 46 samples were obtained from women (mean age, 37.40 years) without complaints related to endometriosis. Genomic DNA was extracted using a Wizard $^{\mathbb{B}}$ Genomic DNA Purification kit (Madison, WI, USA) following manufacturer recommendations. DNA integrity was certified with electrophoresis using a $2 \%$ agarose gel stained with $0.5 \mathrm{mg} / \mathrm{mL}$ ethidium bromide and visualized using the video documentation system $\operatorname{VDS}^{\circledR}$ (Amersham Biosciences, USA).

\section{Molecular analysis}

DNA samples were subjected to polymerase chain reaction amplification to determine the presence of GSTM1 and GSTT1 polymorphisms using the following gene sequences: forward, 5'-GAACTCCCTGAAAAGCTAAAGC-3' and reverse, 5'-GTTGGGCTAAATATAC GGTGG-3'; and forward, 5'-TTCCTTACTGGTCCTCACATCTC-3' and reverse, 5'-TCACCG GATCATGGCCAGCA-3', respectively. Amplification for the detection of present/absent polymorphisms of GSTM1 and GSTT1 genes was performed in a volume of $25 \mu \mathrm{L}$. The cycling conditions for the amplification of GSTM1 primers were as follow: initial denaturation at $94^{\circ} \mathrm{C}$ for $5 \mathrm{~min}$ and 35 cycles of denaturation at $94^{\circ} \mathrm{C}$ for $1 \mathrm{~min}$, annealing at $59^{\circ} \mathrm{C}$ for $1 \mathrm{~min}$, and polymerization at $72^{\circ} \mathrm{C}$ for $1 \mathrm{~min}$ until a final extension at $72^{\circ} \mathrm{C}$ for $7 \mathrm{~min}$. The thermocycling protocol for amplification of GSTT1 primers was as follows: initial denaturation at $94^{\circ} \mathrm{C}$ for $5 \mathrm{~min}$ and 35 cycles of denaturation at $94^{\circ} \mathrm{C}$ for $1 \mathrm{~min}$, annealing at $57^{\circ} \mathrm{C}$ for $90 \mathrm{~s}$, and polymerization at $72^{\circ} \mathrm{C}$ for $1 \mathrm{~min}$ until a $72^{\circ} \mathrm{C}$ final extension for $7 \mathrm{~min}$.

Allanalyseswereperformedinduplicate, and thehumanZFX/Ygenewasusedasaninternal control with the following sequences: forward, 5'-ACCRCTGTACTGACTGTGATTACAC-3' and reverse, 5'-GCACYTCTTTGGTATCYGAGAAAGT-3'. The product obtained from each reaction was subjected to electrophoresis on $2 \%$ agarose gel in an electric field of $10 \mathrm{~V} / \mathrm{cm}$, stained with $5 \mu \mathrm{g} / \mathrm{mL}$ ethidium bromide, and visualized and recorded with the aid of a video documentation system (Image Master VDS ${ }^{\circledR}$, Amersham Pharmacia Biotech).

\section{RESULTS}

Table 1 shows the genotypic frequencies of the GSTM1 and GSTT1 genes in the endometriosis and control groups. In the endometriosis group, the frequency of the presence of the GSTM1 gene was approximately double $(50 \%)$ that of the control group (26\%), and this difference was statistically significant $(P=0.0162)$. The frequency of the GSTT1 polymorphism was 1.65 times higher in the endometriosis group (68\%) compared to that in the control group (41\%), and this difference was statistically significant $(\mathrm{P}=0.0086)$. 
The correlation of the frequency of the Arg/Arg and Arg/Pro + Pro/Pro alleles of p53 associated with the GSTM1 and GSTT1 polymorphisms between the endometriosis group (N $=50)$ and the control group $(\mathrm{N}=46)$ is shown in Table 2. The association of the GSTM1 gene with Arg/Arg had twice the frequency in the endometriosis group (20\%) compared to that in the control group (10\%), and the association of GSTM1 polymorphisms with Arg/Pro + Pro/ Pro was 3 times higher in the endometriosis group (30\%) compared with that in the control group $(10 \%)$. These differences were significant $(\mathrm{P}=0.0046)$. The frequency of GSTT1 null associated with Arg/Arg was 4 times higher in the control group (35\%) compared to that in the endometriosis group (8\%), and the frequency of GSTT1 present associated with Arg/Pro + Pro/Pro was approximately 2 times higher in the endometriosis group $(40 \%)$ compared to that in the control group (17\%). These differences were significant $(\mathrm{P}=0.0070)$.

\begin{tabular}{|c|c|c|c|c|c|}
\hline \multirow[t]{2}{*}{ Variables } & \multicolumn{2}{|c|}{ Endometriosis } & \multicolumn{2}{|c|}{ Control } & \multirow[t]{2}{*}{$\mathrm{P}$} \\
\hline & $\%$ & $\mathrm{~N}$ & $\%$ & $\mathrm{~N}$ & \\
\hline \multicolumn{6}{|l|}{ GSTM1 } \\
\hline Present & 50 & 25 & 26 & 12 & 0.0162 \\
\hline Null & 50 & 25 & 74 & 34 & \\
\hline Total & 100 & 50 & 100 & 46 & \\
\hline \multicolumn{6}{|l|}{ GSTT1 } \\
\hline Present & 68 & 34 & 41 & 19 & 0.0086 \\
\hline Null & 32 & 16 & 59 & 27 & \\
\hline Total & 100 & 50 & 100 & 46 & \\
\hline
\end{tabular}

$\mathrm{P}$ value based on the $\chi^{2}$ test.

Table 2. Distribution of GSTM1, GSTT1 and p53 in endometriosis (endo) and control groups.

\begin{tabular}{|c|c|c|c|c|c|}
\hline \multirow[t]{2}{*}{ Genotype } & \multicolumn{2}{|c|}{ Endometriosis } & \multicolumn{2}{|c|}{ Control } & \multirow[t]{2}{*}{$\mathrm{P}$} \\
\hline & $\%$ & $\mathrm{~N}$ & $\%$ & $\mathrm{~N}$ & \\
\hline GSTM1 + Arg/Arg & 20 & 10 & 10 & 4 & 0.0046 \\
\hline GSTM1null + Arg/Arg & 16 & 8 & 48 & 19 & \\
\hline GSTM1 + Arg/Pro + Pro/Pro & 30 & 15 & 10 & 4 & \\
\hline GSTM1null + Arg/Pro + Pro/Pro & 34 & 17 & 32 & 13 & \\
\hline Total & 100 & 50 & 100 & 40 & \\
\hline GSTT1 + Arg/Arg & 28 & 14 & 23 & 9 & 0.0070 \\
\hline GSTT1null + Arg/Arg & 8 & 4 & 35 & 14 & \\
\hline GSTT1 + Arg/Pro + Pro/Pro & 40 & 20 & 17 & 7 & \\
\hline GSTT1null + Arg/Pro + Pro/Pro & 24 & 12 & 25 & 10 & \\
\hline Total & 100 & 50 & 100 & 40 & \\
\hline
\end{tabular}

$\mathrm{P}$ value based on the $\chi^{2}$ test.

\section{DISCUSSION}

The present study found a higher frequency of absence of the GSTM1 (61\%) and GSTT1 genes $(45 \%)$ in the women studied $(\mathrm{N}=96)$, including those with and without endometriosis, and these results corroborate with those in the literature, as most of the subjects indicated that they were white $(\mathrm{N}=71)$. Based on ethnicity, Gattas and Soares-Vireira (2000) investigated mutations in the genes of healthy individuals from São Paulo, Brazil, including 206 white and 
86 black subjects, and found that the GSTM1 null genotype was significantly more frequent among white subjects $(60.2 \%)$ compared to the frequency in black subjects $(41.9 \%)$. Arruda et al. (1998) have studied the null GSTM1 and GSTT1, with respect to ethnicity genotypes in a group of Brazilian subjects from 3 regions of the country, north, northeast, and southeast, and found a higher frequency of GSTM1 null among white subjects (55\%), followed by $33 \%$ in black subjects and 20\% among the Amazonian Indians. The GSTT1 null genotype was found to have a homogeneous distribution among the descendants of white and black subjects (18.5 and $19 \%$, respectively) and a lower frequency among Amazonian Indian descendants (11\%). Cotton et al. (1999) have reported that the frequency of the GSTT1 null genotype is lower than that of the GSTM1 genotype in African, African American, and white populations, with a frequency range in Africans between 15 and 26\% and between 10 and 21\% in Europeans.

We observed that patients with endometriosis displayed a higher presence of GSTM1 and GSTT1 genes, whereas the control group (patients without clinical signs related to endometriosis) displayed a greater absence of these genes, suggesting that GSTM1 and GSTT1 are unrelated to the cell proliferation of endometriosis. The control group was not diagnosed using the gold standard for endometriosis owing to the invasiveness of the examination; instead, diagnosis was performed using video laparoscopy (Abram et al., 2007). Our next step will be to evaluate the GSTM1 and GSTT1 polymorphisms in a group of patients undergoing laparoscopy with no confirmatory diagnosis of endometriosis.

A study by Hur et al. (2004) found no association between GSTM1 and GSTT1 polymorphism and the development of endometriosis. This study was conducted in Korean women to analyze polymorphic GSTM1, GSTT1, and GST pi 1 and endometriosis and included 194 women with endometriosis confirmed by laparoscopy and 259 who underwent laparoscopy and laparotomy without diagnosis of the disease (control). No significant difference was found between the endometriosis group (57.7\%) and the control group (56\%) for the GSTM1 null polymorphism. The same results were found for the GSTT1 polymorphism: 53.6\% of subjects in the endometriosis group and $48.3 \%$ in the control group displayed absence of the gene. The authors analyzed the same gene sequences examined in the present study.

Jun et al. (2003) have found significant frequency of both the GSTM1 and GSTT1 null genotypes, $72.1 \%(49 / 68)$ and $77.9 \%(53 / 68)$, respectively, in patients with andometriosis $(\mathrm{N}=68)$ compared with controls $(\mathrm{N}=28)$, who displayed $42.9 \%(12 / 28)$ GSTM1 null and $32.1 \%(9 / 28)$ null GSTT1. The authors analyzed the same GSTT1 gene sequence examined in the present study, but the sequence of the GSTM1 null genotype was different.

We studied the association of the p53 gene codon 72 with GSTM1 and GSTT1 polymorphisms among women with endometriosis and women without clinical signs of the pathology and found a significant association that suggested that these polymorphisms may act as a risk factor for the proliferation of endometriosis. Ribeiro et al. (2009) have found a similar result in an evaluation of the p53 codon 72 polymorphism in 2 groups of patients with endometriosis - one with detected infertility and the other without. No significant difference in distribution of the $\mathrm{p} 53$ codon 72 polymorphism was observed between the groups $(\mathrm{P}=$ 0.0974). However, a significant association was found with pain intensity in homozygous or heterozygous patients for the Pro allele $(\mathrm{P}<0.001)$. The presence of the Pro allele is more closely related to patients with infertility and with a more severe clinical presentation of the disease. The authors concluded that the $\mathrm{p} 53$ polymorphism may be used as a molecular marker for endometriosis associated with infertility and worsened symptoms and therefore as an aid 
in the diagnosis, prognosis, counseling, and treatment of the disease.

The frequency of the GSTM1 and GSTT1 null polymorphisms was 61 and $45 \%$ in the endometriosis (fertile and infertile) and control groups, respectively, which agrees with results published in the literature given that our study group was composed mostly of white women, which have a higher frequency of absence of these genes. The GSTM1 and GSTT1 null polymorphisms had no statistically significant relationship to the proliferation of endometriosis.

The frequency of the Arg/Arg allele with the GSTM1 null polymorphism was 3 times higher in the control group compared with that in the endometriosis group, and the presence of GSTM1 associated with these alleles in the endometriosis group was twice that in the control group. The presence of the Arg/Arg allele with GSTT1 null in the control group was 4 times as frequent as that in the endometriosis group. The frequency of the Arg/Pro + Pro/Pro alleles associated with the presence of GSTM1 polymorphism in women with endometriosis was 3 times higher than that in the control group. The frequency of the Arg/Pro + Pro/Pro alleles associated with the presence of GSTT1 in the group with endometriosis was approximately twice that of the control group.

\section{ACKNOWLEDGMENTS}

I thank my advisor K.K.V.O. Moura for their support and encouragement. Research supported by the Catholic University of Goiás, Goiânia, Brazil (UCG / Prope / MGene). We are grateful to the Center for Fetal Medicine and Human Reproduction - fertile conduct for allowing us to this research.

\section{REFERENCES}

Abraham NS, Byrne CM, Young JM and Solomon MJ (2007). Meta-analysis of non-randomized comparative studies of the short-term outcomes of laparoscopic resection for colorectal cancer. ANZ J. Surg. 77: 508-516.

American Society for Reproductive Medicine (2012). Endometriosis. A Guide for Patients Revised. American Society for Reproductive Medicine, Birmingham.

Arruda VR, Grinolli CE, Gonçalves MS, Soares MC, et al. (1998). Prevalence of homozygozity for the deleted alleles of glutathione S-transferase mu (GSTM1) and theta (GSTT1) among distinct ethnic groups from Brazil: Relevance to environmental carcinogenesis. Clin. Genet. 54: 210-214.

Attar R, Cacina C, Sozen S, Attar E, et al. (2010). DNA repair genes in endometriosis. Genet. Mol. Res. 9: 629-636.

Cotton SC, Sharp LJ and Brockton N (1999). Glutathione S transferase polymorphisms and colorectal cancer. Am. J. Epidemiol. 1-18.

Dunselman GA, Groothuis PG, de Goeij AF and Evers JL (2001). The Mesothelium, Teflon or Velcro? Mesothelium in endometriosis pathogenesis. Hum. Reprod. 16: 605-607.

Ertunc D, Aban M, Tok EC, Tamer L, et al. (2005). Glutathione-S-transferase P1 gene polymorphism and susceptibility to endometriosis. Hum. Reprod. 20: 2157-2161.

Farquhar C (2007). Endometriosis. BMJ 334: 249-253.

Gattás GJF and Soares-Vieira JÁ (2000). Cytochrome P450-2E1 and glutathione S-transferase polymorphisms among Caucasians and mulattoes from Brazil. Occup. Med. 50: 508-511.

Guo SW (2005). Glutathione S-transferases M1/T1 gene polymorphisms and endometriosis: a meta-analysis of genetic association studies. Mol. Hum. Reprod. 11: 729-743.

Halis G, Mechsner S and Ebert AD (2010). The diagnosis and treatment of deep infiltrating endometriosis. Dtsch. Arztebl. Int. 107: 446-455.

Hur SE, Lee JY, Moon HS and Chung HW (2004). Polymorphisms of the genes encoding the GSTM1, GSTT1 and GSTP1 in Korean women: no association with endometriosis. Mol. Hum. Reprod. 11: 15-19.

Jackson B and Telner DE (2006). Managing the misplaced: approach to endometriosis. Can. Fam. Physician. 52: 14201424. 
Jun L, Xinmei Z, Yuli Q, Yinghui Y, et al. (2003). Glutathiona S-transferase M1 and T1 genotypes and endometriosis risk: a case-controlled study. Chin. Med. J. 116: 777-780.

Kyama CM, Debrock S, Mwenda JM and D'Hooghe TM (2003). Potential involvement of the immune system in the development of endometriosis. Reprod. Biol. Endocrinol. 1: 123.

Nakata LC, Goloni-Bertollo EM, Santos I, Oliani AH, et al. (2004). Biomarcadores de suscetibilidade à endometriose. Rev. Bras. Ginecol. Obstet. 26: 299-304.

Porpora MG, Medda E, Abballe A, Bolli S, et al. (2009). Endometriosis and organochlorinated environmental pollutants: a case-control study on Italian women of reproductive age. Environ. Health Perspect. 117: 1070-1075.

Ribeiro Júnior CL, Arruda JT, Silva CTX and Moura KKVO (2009). Analysis of p53 codon 72 gene polymorphism in Brazilian patients with endometriosis. Genet. Mol. Res. 8: 494-499. 